Original Research Paper

\title{
Daily Living Activities of Home-Bound Elderly in a Northern Thai Suburban Community
}

\author{
${ }^{1}$ Supawadee Putthinoi, ${ }^{1}$ Suchitporn Lersilp and ${ }^{2}$ Nopasit Chakpitak \\ ${ }^{I}$ Department of Occupational Therapy, Faculty of Associated Medical Sciences, Chiang Mai University, \\ 110 Intawaroroj Rd., Chiang Mai 50200, Thailand \\ ${ }^{2}$ International College, Chiang Mai University, 239 Huaykaew Rd., Chiang Mai 50200, Thailand
}

Article history

Received: 15-05-2016

Revised: 05-11-2016

Accepted: 11-11-2016

Corresponding Author:

Supawadee Putthinoi

Department of Occupational

Therapy, Faculty of Associated

Medical Sciences, Chiang Mai

University, 110 Intawaroroj

Rd., Chiang Mai 50200,

Thailand

Email: supawadee.p@cmu.ac.th

\begin{abstract}
The world including Thailand is facing up to a rapidly growing ageing population. In order to reduce the need of care for elderly people, they must be enabled to carry out basic activities at home, which are associated with safe and independent daily living. The purpose of this study was to examine the ability of elderly people in performing their daily activities while living at home in the community of Namprae and Sanklang villages, Chiang Mai, Thailand. The Activities of Daily Living (ADL) assessment was developed to measure functional status based on the International Classification of Functioning (ICF) concept. Data collection included interviews with the subjects and observation of their performance at their home and in the community. The study found that all of the elderly people communicated (spoke, produced non-verbal messages and conversed) independently. The majority also acted independently in eating and drinking, but they needed some assistance from people or equipment in activities such as driving, preparing meals, doing housework, moving around, washing and walking. Most of the home-bound elderly people performed ADL independently, whereas, they depended on transportation and driving while living at their home. Thai people, especially in the elderly section, have been influenced strongly by religion (Buddhism) in a spiritual dimension, but about half of the participants in this study had limitations in religion and spirituality. This situation created an environmental barrier that caused the limitation of physical function in elderly people when performing ADL.
\end{abstract}

Keywords: Activities of Daily Living, Community, Elderly, Home-Bound, International Classification of Functioning

\section{Introduction}

In 2005, Thailand entered the global trend of growing ageing populations (NCE, 2013) which will level out by 2021 (Prasartkul, 2013). The rapid growth of elderly people in Thailand is of concern and needs a significant response. Age-related changes frequently have an adverse impact on health and quality of life, which need more in the way of assistance. Thus, effective healthcare intervention should encourage elderly people to stay healthy throughout their old age, which is a strategy ideal for reducing the financial pressures and demands on the healthcare service. "Ageing in place" is a popular term used for healthy ageing and living safely and independently in the places where these people live (Taira and Carlson, 2009). It is a multiple interacting process that operates from housing elderly people to their living in the community with independence and autonomy (Wiles et al., 2012; Hillcoat-Nallétamby, 2014; Putthinoi et al., 2015). Successfully performing Activities of Daily Living (ADL) is required for "ageing in place", which maintains the quality of life for elderly people in the community. ADL performance also shows evidence of healthy ageing (Lawton, 1990; Fausset et al., 2011). Elderly people should retain the ability to perform ADL independently in their own home as long as possible.

The World Health Organization (WHO; 2004; 2007) has an ageing framework to enhance the quality of life in all areas of the community in age-friendly regions. Furthermore, the WHO (2008) report on renewal of Primary Health Care (PHC) focuses on building and strengthening the community health system. Thus, the 
main function is to enable elderly people to live effectively in their own home at the community level. Reform of community health in Thailand has been initiated in line with government decentralization in order to strengthen primary healthcare by the community or local governments (Maeseneer et al., 2008). Therefore, the Thai healthcare system has shifted some responsibility to local authorities at the provincial level (municipal and general hospitals), which focus on primary healthcare in the community such as community health posts and village and sub-district primary healthcare centers (Sakunphanit, 2015). Promotion of elderly people living independently in their community is within the scope of primary healthcare services under responsibility of the local authority. This research was carried out to strengthen primary healthcare at the village level and support the ageing population in Thailand. Understanding the ability of elderly people to perform their daily activities at the community level is needed in order to develop solutions that provide care, support and well-being within the "ageing in place" concept.

The International Classification of Functioning, Disability and Health (ICF) is a conceptual framework used as a multiple interaction between the health of a person and environmental and personal factors (WHO, 2013). It has been used in many different contexts as a tool for statistical, research, clinical, social policy and educational purposes and applied, not only in the health sector, but also for many different purposes worldwide (Stucki et al., 2003; Reed et al., 2005; Bostan et al., 2014). It has the potential to determine functional status on activities and participation components that are associated with living independently, with "ageing in place" and primary healthcare at the village level. The primary care service for elderly people is divided into three groups: Well, home-bound and bed-bound. Providing care for home-bound elderly people focuses on them living independently in their own home (Peachpansri et al., 2014). The aim of this study was to apply ICF as a tool to evaluate the ADL performance of elderly people living at home. This study can shape the development of better primary healthcare services that are suitable for home-bound elderly people in the community.

\section{Materials and Methods}

This study was approved by the local ethical committee of the Faculty of Associated Medical Sciences, Chiang Mai University. A cross-sectional descriptive study was conducted in the community of Namprae and Sanklang villages, Chiang Mai, Thailand over a 12 month period. Two settings, with a district health promotion hospital located in the same province, conducted home visits to provide healthcare services for elderly people. These settings were selected for convenient sampling of community dwellings for an on-going community-based study and representation of an urbanized area. Moreover, only two communities were chosen because the researcher could contact and work easily with all of the study participants, who were elderly people living in the community and aged 60 years and older. The names and addresses of all the home-bound elderly people in the community were listed from the database at the district health promotion hospital. Elderly people, without severely impaired cognitive function, were considered as home-bound if they needed help in leaving their home. In which case, a letter was sent inviting them to participate in this study and a total of 97 elderly people consented to take part, with 46 and 51 of them from Namprae village and Sanklang village, respectively. After receiving the letter, consenting home-bound elderly people were contacted by the researcher and an appointment to meet at their home was arranged. Of 97 participants, 73 completed responses and measurements because 10 were transferred to hospital, 11 changed to bed-bound status and 3 moved to other villages, meaning 24 participants were excluded.

An assessment tool was divided into two parts: (1) socio-demographic information on age, gender and marital status, condition of health, comorbidities and physical disability and (2) ADL assessment. Assessment of ADL performance was based on a list in the ICF, Disability and Health framework. Providing care for elderly people in the community included community people, community-based health professionals, local government, the health workforce and people from sectors outside health or non-governmental organizations. The ICF could provide all categories of demands from elderly people living in community as well as a common language for communicating between various groups in community services. Thus, this study used the ICF to develop its assessment tool.

The first version of assessment was developed based on the ICF categories from activities and participation components and covered the full range of life areas represented by the letter "d" (from Chapter d1 to d9). The numerical code started with the chapter number (one digit, "d1"), followed by the second level (two digits, "dlxx") and third level (one extra digit, "d115x"), which were arranged in a coded hierarchy (Chapter and Category domain), as shown in Fig. 1. This means that a high level was wider than the lower one.

A content validation step was followed by a panel of five experts (Lynn, 1986), in order to select the ICF with the highest consensus (4 in 5) being the final version. Of the five experts, three were teaching and/or practicing in areas of ICF, Disability and Health and two worked in the area of elderly people in the community. The final version contained 30 activities/items that were more specific to home-bound elderly people in the Thai community context, as shown in Table 2 . The rating was modified from a generic qualifier to a two-point scale: (1) independent (no problem) and (2) dependent (mild, moderate, severe and complete problem). 


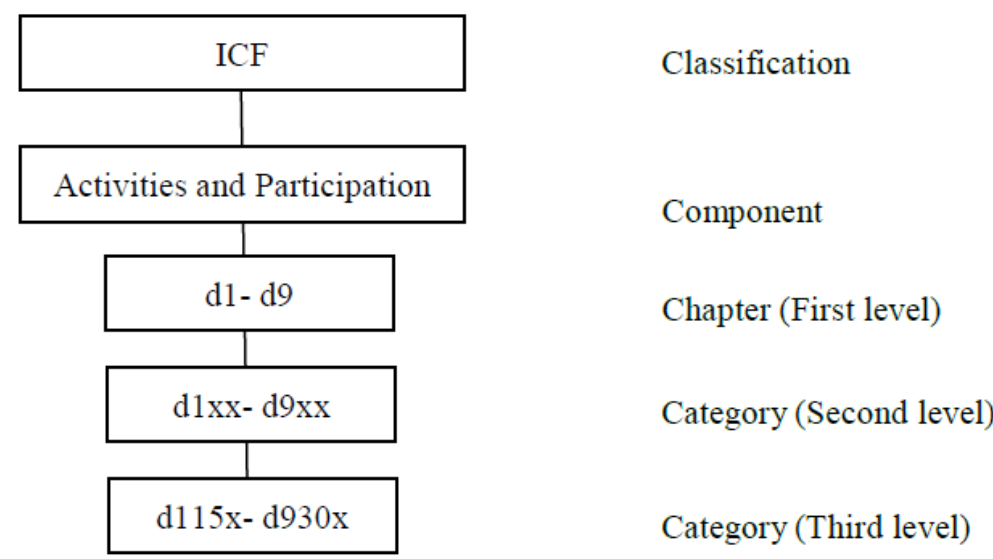

Fig. 1. ADL assessment based on the ICF framework (WHO, 2001)

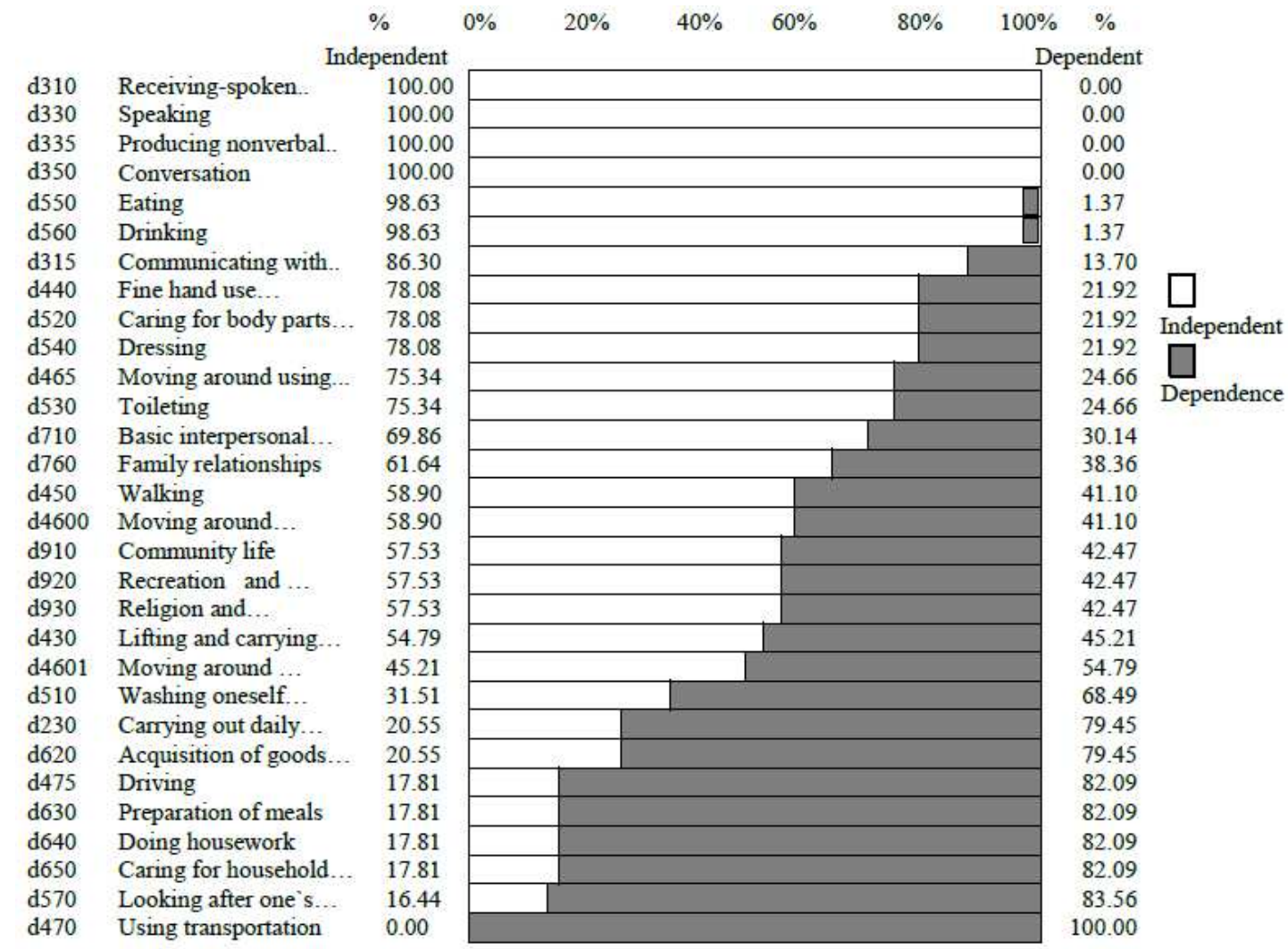

Fig. 2. Ratio between independent and dependent ADL performance

Assessment of each elderly person was conducted for ADL performance by two trained research assistants, who were fourth-year occupational therapy students. Data on all of the accepted participants were collected from interviews and by direct observation of the ADL performance at the home of the elderly people. The home-bound elderly people served as major informants, while family members and village healthcare volunteers served as secondary informants. The performance of ADL was interpreted by whether the subjects were dependent or independent. Demographics and ADL performance were analyzed by using descriptive statistics to calculate frequency and percentage.

\section{Results}

Overall, the 73 home-bound elderly participants ( $75.26 \%$ of the target population) were investigated thoroughly in the community. The results were divided into two parts: (1) Demographic profile and (2) ADL performance. 
Table 1. Characteristics of the home-bound elderly people $(\mathrm{N}=73)$

\begin{tabular}{lrr}
\hline Demographic data & Number of respondents & Percentage (\%) \\
\hline Age (years) & 14 & 19.18 \\
$60-69$ & 21 & 28.77 \\
$70-79$ & 31 & 42.47 \\
$80-89$ & 7 & 9.59 \\
$>90$ & 21 & 28.77 \\
Gender & 52 & 71.23 \\
Male & & 17.81 \\
Female & 13 & 42.47 \\
Marital status & 31 & 39.73 \\
Single & 29 & 100.00 \\
Married & & \\
Other & 73 & 90.41 \\
Religion & 66 & 9.59 \\
Buddhist & 7 & 2.74 \\
Living arrangements & & 97.26 \\
Living with one or more young adults & 2 & 19.18 \\
Living alone & 71 & 60.27 \\
Chronic health conditions & & 17.81 \\
Yes & 14 & 4.11 \\
Physical disabilities* & 44 & 3 \\
No disabilities & 13 & \\
Mobility impairment & 3 & \\
Visual impairment & & \\
Hearing impairment & & \\
\hline
\end{tabular}

* More than one answer

Table 2. Performance of ADL in the home-bound elderly people $(\mathrm{N}=73)$

\begin{tabular}{|c|c|c|}
\hline Activities of daily living & $\begin{array}{l}\text { Independent } \\
\text { number (\%) }\end{array}$ & $\begin{array}{l}\text { Dependent } \\
\text { number }(\%)\end{array}$ \\
\hline \multicolumn{3}{|l|}{ d2. General tasks and demands (general aspects of carrying out tasks) } \\
\hline d230 Carrying out daily routine & $15(20.55)$ & $58(79.45)$ \\
\hline \multicolumn{3}{|l|}{ d3. Communication (general and specific features of communicating) } \\
\hline d310 Communicating with-receiving-spoken messages & $73(100.00)$ & - \\
\hline d315 Communicating with-receiving-nonverbal messages & $63(86.30)$ & $10(13.70)$ \\
\hline d330 Speaking & $73(100.00)$ & - \\
\hline d335 Producing nonverbal messages & $73(100.00)$ & - \\
\hline $\mathrm{d} 350$ Conversation & $73(100.00)$ & _ \\
\hline \multicolumn{3}{|l|}{ d4. Mobility } \\
\hline d430 Lifting and carrying objects & $40(54.79)$ & $33(45.21)$ \\
\hline d440 Fine hand use (picking up, grasping, manipulating, releasing) & $57(78.08)$ & $16(21.92)$ \\
\hline d450 Walking (short distances, long distances, on different surfaces, etc.) & $43(58.90)$ & $30(41.10)$ \\
\hline $\mathrm{d} 4600$ Moving around within the home & $43(58.90)$ & $30(41.10)$ \\
\hline d4601 Moving around within buildings other than home & $33(45.21)$ & $40(54.79)$ \\
\hline d465 Moving around using equipment & $55(75.34)$ & $18(24.66)$ \\
\hline d470 Using transportation (car, bus, train, plane, etc.) & & $73(100.00)$ \\
\hline d475 Driving (riding bicycle and motorbike, driving car, etc.) & $13(17.81)$ & $60(82.09)$ \\
\hline \multicolumn{3}{|l|}{ d5. Self-care } \\
\hline d510 Washing oneself (bathing, drying, washing hands, etc.) & $23(31.51)$ & $50(68.49)$ \\
\hline d520 Caring for bodily parts (skin, teeth, hair, fingernails, etc.) & $57(78.08)$ & $16(21.92)$ \\
\hline d530 Toileting & $55(75.34)$ & $18(24.66)$ \\
\hline d540 Dressing & $57(78.08)$ & $16(21.92)$ \\
\hline d550 Eating & $72(98.63)$ & $1(1.37)$ \\
\hline d560 Drinking & $72(98.63)$ & $1(1.37)$ \\
\hline d570 Looking after one`s health & $12(16.44)$ & $61(83.56)$ \\
\hline \multicolumn{3}{|l|}{ d6. Domestic life } \\
\hline d620 Acquisition of goods and services (shopping, etc.) & $15(20.55)$ & $58(79.45)$ \\
\hline d630 Preparation of meals (simple and complex meals) & $13(17.81)$ & $60(82.09)$ \\
\hline d640 Doing housework (cleaning house, washing dishes and laundry, ironing, etc.) & $13(17.81)$ & $60(82.09)$ \\
\hline d650 Caring for household objects & $13(17.81)$ & $60(82.09)$ \\
\hline \multicolumn{3}{|l|}{ d7. Interpersonal interactions and relationships } \\
\hline d710 Basic interpersonal interactions & $51(69.86)$ & $22(30.14)$ \\
\hline d760 Family relationships & $45(61.64)$ & $28(38.36)$ \\
\hline \multicolumn{3}{|l|}{ d9. Community, social and civic life } \\
\hline d910 Community life & $42(57.53)$ & $31(42.47)$ \\
\hline d920 Recreation and leisure & $42(57.53)$ & $31(42.47)$ \\
\hline d930 Religion and spirituality & $42(57.53)$ & $31(42.47)$ \\
\hline
\end{tabular}


The characteristics and ADL ability of the participants are presented in Table 1 and 2, respectively. Almost all of the home-bound elderly $(97.2 \%)$ had a chronic health condition that included any one of the following; heart disease, high blood pressure, arthritis, asthma or diabetes. A majority of them $(60.27 \%)$ had physical disabilities that limited their ability to carry out ADL independently. ADL performance of the elderly was analyzed as independent or dependent in ICF, Disability and Health categories, as shown in Table 1. Description of ADL performance with scales of 0,20 , 40, 60, 80 and $100 \%$ is presented in Fig. 2.

A total of 20 from 30 ICF categories of activities and participation were reported (over $50 \%$ of participants) as significantly independent. The majority $(79.45 \%)$ of the home-bound elderly people were dependent in d230 in carrying out their daily routine and in the sublevel of $\mathrm{d} 2$ (general tasks and demands), they needed assistance in completing a daily routine such as making plans for activities throughout the day. The elderly participants were significantly independent (at least $86.30 \%$ ) in $\mathrm{d} 3$ (communication), in that they had no problem with basic actions in general and specific features of communication in order to perform more complex tasks in socially collaborative situations. The main problems according to frequencies were reported as dependent in d6 (domestic life).

\section{Discussion}

This study identified ADL performance under the ICF activities and participation categories by home visit evaluation. The study sample represented elderly people in two villages in order to identify their functioning without severely impaired cognition. Thirty categories of ICF activities and participation categories were validated for more specificity to this particular group of people. ICF Core Sets were applied to describe the functioning of persons with many conditions such as stroke (Algurén et al., 2010), chronic widespread pain, low back pain (Schwegler et al., 2012) and multiple sclerosis (Karhula et al., 2013). This finding enabled the use of ICF, Disability and Health as a tool for distinguishing between independence and dependence among elderly people living in the community.

All of the participants could perform communication tasks independently in $\mathrm{d} 310$ (receiving-spoken messages), d330 (speaking), d335 (producing nonverbal messages) and $\mathrm{d} 350$ (conversation). The functional communication skill was a critical tool that linked to other functions in daily life, including social and leisure activities, community participation and personal relationships (Yorkston et al., 2010). Although decline in communication is associated with ageing, the elderly people in this study had the ability to communicate successfully, which was advantageous in obtaining primary healthcare in the community. Limited communication is usually common, especially in a hospital setting (Ebert and Heckerling, 1998). Elderly people should preserve and enhance their ability to communicate in order to maintain social roles and identity and access needed services such as healthcare.

Surprisingly, all of the participants could not use d470 (transportation) independently. Furthermore, d475 (driving) was a problem for most of the elderly people $(82.09 \%)$. The reasons for this might include barriers, such as lack of public and affordable transportation, poor access to transportation, physical geographic problems and poor public bus services. Transportation is a primary function in conjunction with other purposes, for example, maintaining social contact, travelling to appointments and shopping (Cho et al., 2010). It is a strong link to satisfaction with life (Coughlin, 2001). Providing accessible transportation to enable active ageing people to travel is a challenge and various policy options are needed to close the gap of transportation in Thailand.

Dependence was frequently seen mostly in d570 (looking after one's health), d650 (caring for household objects), d640 (doing housework), d630 (preparation of meals), d620 (acquisition of goods and services), d230 (carrying out daily routine) and d510 (Washing oneself). The elderly people could not participate in community life activities because achieving these tasks concerns the ability of personal engagement in the living context. There are more complex tasks involved with domestic life and community participation. These problems may need the responsibility of building community strength in order to provide service systems for home-bound elderly people living independently. Fricke (2010) similarly reported that domestic and community activities usually have limitations in old age.

The following six categories; d550 (eating), d560 (drinking), d520 (caring for bodily parts), d540 (dressing), d315 (receiving-nonverbal messages) and d440 (fine hand use), were not a problem in almost all of the participants. Fundamental self-care activities of daily living can be classified into basic ADL such as personal care; for example, eating, drinking and dressing. These activities relate to active ageing (Dale et al., 2012) and are very critical for elderly people when being discharged from hospital and entering the community (Turcotte et al., 2015). Thus, successfully performing basic ADL tasks is very important for achieving quality of life in daily living within the community.

In the perspective of $\mathrm{d} 460$ (moving around in different locations), around half of the participants were dependent in $\mathrm{d} 450$ (walking), d4600 (moving around within the home) and $\mathrm{d} 4601$ (moving around within buildings other than their home), whereas more participants $(75.34 \%)$ had no problem with $\mathrm{d} 465$ 
(moving around by using equipment). Home-bound elderly people had limitation in mobility mainly when living in their home. They need assistance from caregivers or health volunteers in performing this activity. However, equipment or assistive devices such as a wheelchair or walker can facilitate moving around within their home and within buildings other than their home. Most elderly people, who live in the community, commonly use devices (cane, walker, wheelchair and scooter) to overcome their limitation in mobility (Freedman et al., 2005). The ability of elderly people to move around in various places is a basic to more complex activity such as transportation. Mobility restriction contributes to a decline in social participation and quality of life (Whelan et al., 2006). Thus, health professionals can make home visits to provide additional support services and enable mobility to function.

A surprisingly large number of participants (75.34\%) was independent in d530 (toileting), which involved planning and carrying out and disposing of human waste (urine and feces), as well as cleaning oneself afterwards (WHO, 2001). Respect for seniority has been an integral part of Thai culture. Toileting with no privacy can cause great discomfort and embarrassment as Thai elderly people are sensitive emotionally (Israsena $\mathrm{Na}$ Ayudhya et al., 2007). Thus, these values encouraged participants to use assistive technology such as raised toilet seats, grab bars and anti-slip rubber mats to help them be independent. However, this activity needed assistance from caregivers, when the participants had chronic health conditions and physical disabilities.

Almost half of the participants had limitations in $\mathrm{d} 9$ (community, social and civic life). Regarding limitations in d910 (community life), d920 (recreation and leisure) and $\mathrm{d} 930$ (religion and spirituality), the actions and tasks required are associated with engagement in organized social life outside the family, in the community and in social and civic areas of life (WHO, 2001). Several reasons for these limitations are associated with personal values and interests as well as individual contexts. However, these tasks are related to higher quality of life by feeling part of the community and leading a more active and healthier existence (Iwasaki and Mannell, 2000). Although there is a gradual decline in the health and functioning of elderly people, socially active community life is important in helping them cope with stress or overall mental health by creating a sense of balance.

Approximately $93.6 \%$ of the Thai population are Buddhist (NSO, 2009), as were all of the participants in this study. Thus, beliefs, values and traditions in Thai society come from Buddhism. The Thai Buddhist society is generated as "space" for the elderly people within the belief system. Most Thai elderly people play leading roles in religious practices, which are accepted well within the community (Sasiwongsaroj et al., 2012). Engaging in religious or spiritual activities involves attending a temple and offering food to monks on a Buddhist holy day/during Buddhist lent/religious day. However, d930 (religion and spirituality) was limited in about half of the participants in this study. Limitations in the performance of religious activities were caused by related tasks such as transportation, preparing meals and mobility. Nevertheless, religious space should overcome these limitations and support the ageing population in enhancing their well-being.

\section{Conclusion}

The 30 ICF activities and participation categories can be used for assessing and structuring ADL performance in functioning and disability. This study focused on the importance of ageing in place, in which elderly people are living at home. Almost all homebound elderly people can perform activities independently in the community context in Thailand, where categories of $\mathrm{d} 3$ (communication), for example, d310 (receiving-spoken messages), d330 (speaking), d335 (producing nonverbal messages) and d350 (conversation) and those of d5 (self-care); d550 (eating) and d560 (drinking), apply. Unfortunately, the most frequently reported limitations comprised $\mathrm{d} 470$ (using transportation), d570 (looking after one`s health), d650 (caring for household objects), d640 (doing housework), d630 (preparing meals) and d475 (driving). Dysfunctions of ADL performance in ageing are considered to be activity limitations within the I CF, Disability and Health framework. Practical feasibility of the ICF Core Set could become a helpful tool in developing potential solutions for primary healthcare professionals to promote healthy ageing and support "ageing in place". The further analysis, cross-tabulation of the socio-demo characteristics, i.e., disability with the ADL of home-bound elderly people could be provided to better understand the ADL problems.

\section{Acknowledgement}

The authors thank all of the participants from Namprae and Sanklang villages for allowing the authors to evaluate using room-by-room observation in their home. Special thanks are expressed to the Research Administration Center, Chiang Mai University for providing valuable impetus for publishing this paper.

\section{Author's Contributions}

Supawadee Putthinoi: Participated in all study, coordinated the data analysis and contributed to the writing of the manuscript. 
Suchitporn Lersilp: Contributed to the data collection and the data analysis.

Nopasit Chakpitak: Designed the research plan and organized the drafting of the article.

\section{Ethics}

The authors declare that there is no conflict of interests regarding the publication of this paper and no ethical issues involved.

\section{References}

Algurén, B., A. Lundgren-Nilsson and K.S. Sunnerhagen, 2010. Functioning of stroke survivorsa validation of the ICF core set for stroke in Sweden. Disabil. Rehabil., 32: 551-559. DOI: $10.3109 / 09638280903186335$

Bostan, C., Oberhauser, G. Stucki, J. Ickenbach and A. Cieza, 2014. Which environmental factors are associated with performance when controlling for capacity? J. Rehabil. Med., 46: 806-813. DOI: 10.2340/16501977-1839

Cho, K.H., Michel, J.P., Bludau, J., Dave and S.H. Park, 2010. Textbook of Geriatric Medicine International. 1st Edn., Argos, Korea, ISBN-10: 8991493203, pp: 460.

Coughlin, J., 2001. Transportation and Older Persons: Perceptions and Preferences: A Report on Focus Groups. 1st Edn AARP, Public Policy Institute, Washington, DC, pp: 20.

Dale, B., U. Söderhamn and O. Söderhamn, 2012. Self-care ability among home-dwelling older people in rural areas in southern Norway. Scand. J. Car. Sci., 26: 113-122. DOI: 10.1111/j.1471-6712.2011.00917.x

Ebert, D.A. and P. Heckerling, 1998. Communication disabilities among medical inpatients. N. Engl. J. Med., 339: 271-273.

DOI: $10.1056 /$ NEJM199807233390416

Fausset, C.B., A.J. Kelly, W.A. Rogers and A.D. Fisk, 2011. Challenges to aging in place: Understanding home maintenance difficulties. J. Hous. Elderly, 25: 125-141. DOI: 10.1080/02763893.2011.571105

Freedman, V.A., E.M. Agree and J.C. Cornman, 2005. Development of an assistive technology and environmental assessment instrument for national surveys: Final report. U.S. Department of Health and Human Services.

Fricke, J., 2010. Activities of Daily Living. In: International Encyclopedia of Rehabilitation. Stone, J.H. and M. Blouin (Eds.).

Hillcoat-Nallétamby, S., 2014. The meaning of "independence" for older people in different residential settings. J. Gerontol. B, 69: 419-430. DOI: $10.1093 /$ geronb/gbu008
Israsena Na Ayudhya, P., N. Boonvong and P. Piromya, 2007. Caregiving for the elderly in Thailand. Proceedings of the 8ht Pan-Pacific Conference on Occupational Ergonomics, Oct. 17-19, Bangkok, Thailand, pp: 1-15.

Iwasaki, Y. and R. Mannell, 2000. Hierarchical dimensions of leisure stress coping. Leisure Sci., 22: 163-181. DOI: 10.1080/01490409950121843

Karhula, M.E., J. Kanelisto, J. Ruutiainen, P.I. Hämäläinen and A.L. Salminen, 2013. The activities and participation categories of the ICF Core Sets for multiple sclerosis from the patient perspective. Disabil. Rehabil., 35: 492-497. DOI: $10.3109 / 09638288.2012 .702845$

Lawton, M.P., 1990. Aging and performance of home tasks. Hum. Factors, 32: 527-536. PMID: 2074107

Lynn, M.R., 1986. Determination and quantification of content validity. Nurs. Res., 35: 382-385. PMID: 3640358

Maeseneer, D.J., S. Moosa, Y. Pongsupap and A. Kaufman, 2008. Primary health care in a changing world. Br. J. Gen. Pract., 58: 806-809. DOI: $10.3399 /$ bjgp08X342697

NCE, 2013. Situation of the Thai Elderly 2012. SS Plus Media Company Limited, National Committee on the Elderly, Thailand.

NSO, 2009. Report on 2008 Survey of the socio-cultural status and mental health. National Statistical Office, Thana Press, Thailand.

Peachpansri, S., S. Viripiromgool, V. Thongcharoen, C. Ronnarithivichai and T. Jamkrajang, 2014. The development of community care model of subdistrict health promoting hospitals for older persons. J. Pub. Health Dev., 12: 31-47.

Prasartkul, P., 2013. Population aging and health: A case study of Thailand. Institute for Population and Social Research Mahidol University, Thailand.

Putthinoi, P., K. Meksamoot, P. Yodmongkol and N. Chakpitak, 2015. Household reverse logistics analysis using the SCOR model to improve home safety of the elderly in the municipality. Int. J. Logist. Syst. Manage., 21: 348-364. DOI: 10.1504/IJLSM.2015.069732

Reed, G.M., J.B. Lux, L.F. Bufka, C. Trask and D.B. Peterson et al., 2005. Operationalizing the international classification of functioning, disability and health in clinical settings. Rehabil. Psychol., 50: 122-131. DOI: 10.1037/0090-5550.50.2.122

Sakunphanit, 2015. Universal health care coverage through pluralistic approaches: Experience from Thailand. National Health Security Office, Thailand.

Sasiwongsaroj, K., S. Pornsiripongse, Y. Burasith, P. Ketjamnong and N. Koosakulrat, 2012. Buddhist temple: The well-being space for the aged in Thailand. J. Popul. Soc. Stud., 20: 2-19. 
Schwegler, U., J. Anner, C. Boldt, A. Glässel and V. Lay et al., 2012. Aspects of functioning and environmental factors in medical work capacity evaluations of persons with chronic widespread pain and low back pain can be represented by a combination of applicable ICF Core Sets. BMC Public Health, 12: 1088-1088. DOI: 10.1186/1471-2458-12-1088

Stucki, G., T. Ewert and A. Cieza, 2003. Value and application of the ICF in rehabilitation medicine. Disabil. Rehabil., 25: 628-938. PMID: 12523361

Taira, E. and J.L. Carlson, 2009. Aging in place: Designing, adapting and enhancing the home environment. Routledge, New York.

Turcotte, P., N. Larivière, J. Desrosiers, P. Voyer and H. Carbonneau et al., 2015. Participation needs of older adults having disabilities and receiving home care: met needs mainly concern daily activities, while unmet needs mostly involve social activities. BMC Geriatrics, 15: 95-95. DOI: $10.1186 / \mathrm{s} 12877-015-0077-1$

Whelan, M., J. Langford, J. Oxley, S. Koppel and J. Charlton, 2006. The elderly and mobility: A review of the literature. Monash University Accident Research Centre, Australia.
Wiles, J.L., A. Leibing, N. Guberman, J. Reeve and R.E. Allen, 2012. The meaning of "aging in place" to older people. Gerontologist, 52: 357-366. DOI: $10.1093 /$ geront/gnr098

WHO, 2001. International Classification of Functioning, Disability and Health: ICF. 1st Edn., World Health Organization, Switzerland, ISBN-10: 9241545445, pp: 228.

WHO, 2004. Active Ageing: Towards Age-friendly Primary Health Care. 1st Edn., World Health Organization, France, ISBN-10: 9241592184, pp: 30.

WHO, 2007. Global Age-Friendly Cities: A Guide. 1st Edn., World Health Organization, France, ISBN-10: 9241547308, pp: 76.

WHO, 2008. Global Age-Friendly Cities: A Guide. 1st Edn., World Health Organization, France.

WHO, 2013. A Practical Manual for using the International Classification of Functioning, Disability and Health (ICF). World Health Organization, Switzerland.

Yorkston, M.S., Bourgeois and C.R. Baylor, 2010. Communication and aging. Phys. Med. Rehabil. Clin. N. Am., 21: 309-319.

DOI: $10.1016 /$ j.pmr.2009.12.011 